\title{
CONSTRUCTION AND DEMOLITION WASTE STREAMS FROM THE MATERIAL RECOVERY POINT OF VIEW: A CASE STUDY OF THE SOUTH KARELIA REGION, FINLAND
}

\author{
MIIA LIIKANEN, JOUNI HAVUKAINEN, KAISA GRÖNMAN \& MIKA HORTTANAINEN \\ Department of Sustainability Science, Lappeenranta University of Technology, Finland
}

\begin{abstract}
The construction and demolition $(C \& D)$ waste industry is a major generator of waste. In the European Union (EU), C\&D waste accounts for $25-30 \%$ of total waste generation. In Finland, the C\&D industry accounted for $14 \%$ of all waste generated in the country in 2015 . The main components of C\&D waste are minerals (e.g. concrete, bricks and ceramics), wood and metals, which offer high potential for material recovery. As a result, the EU has set an ambitious material recovery target for its member states: by $2020,70 \%$ of generated non-hazardous C\&D waste shall be reused, recycled or recovered as material in another manner. In 2014, the material recovery rate of C\&D waste in Finland was 58\%. Further action is therefore needed in order to reach this target. This calls for more accurate monitoring of $C \& D$ waste streams and knowledge of the composition of mixed C\&D waste. In this study, a closer look is taken at $C \& D$ waste streams in the South Karelia region of Finland. The objectives are to quantify regional $C \& D$ waste streams, to estimate the composition of $C \& D$ waste based on the reported waste streams and to assess the composition of mixed C\&D waste based on manually sorted C\&D waste samples from the South Karelia region. By achieving these objectives, the regional material recovery potential of C\&D waste can be estimated. In 2016, the South Karelia region reported the generation of approximately 165,000 tonnes of C\&D waste. This reflects approximately $14 \%$ of the total waste generated in the region. The C\&D waste generated consisted of mineral waste (34\%), metals $(32 \%)$ and soil $(23 \%)$. Additionally, the share of mixed C\&D waste $(6 \%)$ as well as wood, glass and plastic ( $4 \%$ combined) was notable. The manually analysed mixed C\&D waste samples indicate significant material recovery potential as minerals, wood and plastic made up approximately $70 \%$ of the samples.

Keywords: construction and demolition waste, Finland, material recovery, waste management.
\end{abstract}

\section{INTRODUCTION}

The European Union (EU) has set an ambitious material recovery target for EU member states: by $2020,70 \%$ of generated non-hazardous C\&D waste shall be re-used, recycled or recovered as material in another manner [1]. Several member states, such as Germany, Austria and Denmark, have already achieved this target [2], but Finland is still lagging behind. In 2014, 58\% of generated C\&D waste was recovered as material [3]. Therefore, further action is needed over the following years to reach the EU's target.

The definition of C\&D waste varies somewhat across the European Union (EU), hindering cross-country comparisons [4]. In Finland, the C\&D industry includes: (1) the construction of buildings; (2) civil engineering; and (3) specialised construction activities. All waste generated by these activities, including soil and mineral waste, is considered C\&D waste. Thus, if the origin of waste is reported, C\&D waste streams can be identified.

The C\&D industry generates approximately $25-30 \%$ of all waste generated in the EU [4]. In Finland in 2015, approximately 15 million tonnes of C\&D waste were generated. This is equivalent to $14 \%$ of all the waste generated in the country that year [5]. Of these 15 million tonnes of waste, the vast majority (14.6 million tonnes) was soil and mineral waste. 
Excluding soil and mineral waste, wood, metals, glass and plastic are the main characteristics of C\&D waste in Finland [5].

Salmenperä et al. [3] recently evaluated the composition of waste generated by the construction of buildings in Finland. According to their study, mineral waste (e.g. concrete and tiles) and wood are the largest components of C\&D waste. In total, they account for approximately $65 \%$ of $C \& D$ waste. However, the composition of $C \& D$ waste is heavily dependent on the origin of the waste. Therefore, the composition of C\&D waste varies significantly depending on the type of building being constructed or renovated (e.g. residential versus commercial buildings), the age of the building (e.g. the construction materials used) and its location (e.g. differing conditions in different states) [6]. Additionally, the type of site has a substantial impact on the composition of waste, for example, construction sites for new buildings and the renovation of existing ones versus demolition sites.

In this study, we take a closer look at C\&D streams in the South Karelia region of Finland. Firstly, the regional C\&D waste streams are quantified. The objective is to determine how much C\&D waste is generated in the region and the composition of this waste. Secondly, we aim to assess the composition of mixed $C \& D$ waste by manually sorting $C \& D$ waste samples in the region under study.

\section{METHODOLOGY}

\subsection{Description of the case study area}

Finland is a country in Northern Europe. The population of Finland is 5.5 million, and it is a fairly sparsely populated country. Based on population, Finland is the world's 115th largest country, while based on surface area, it is the world's 64th largest. The population density of Finland is 16 inhabitants $/ \mathrm{km}^{2}$. The South Karelia region is located in the south-east of the country (see Fig. 1). The region is home to approximately 130,000 inhabitants [7].

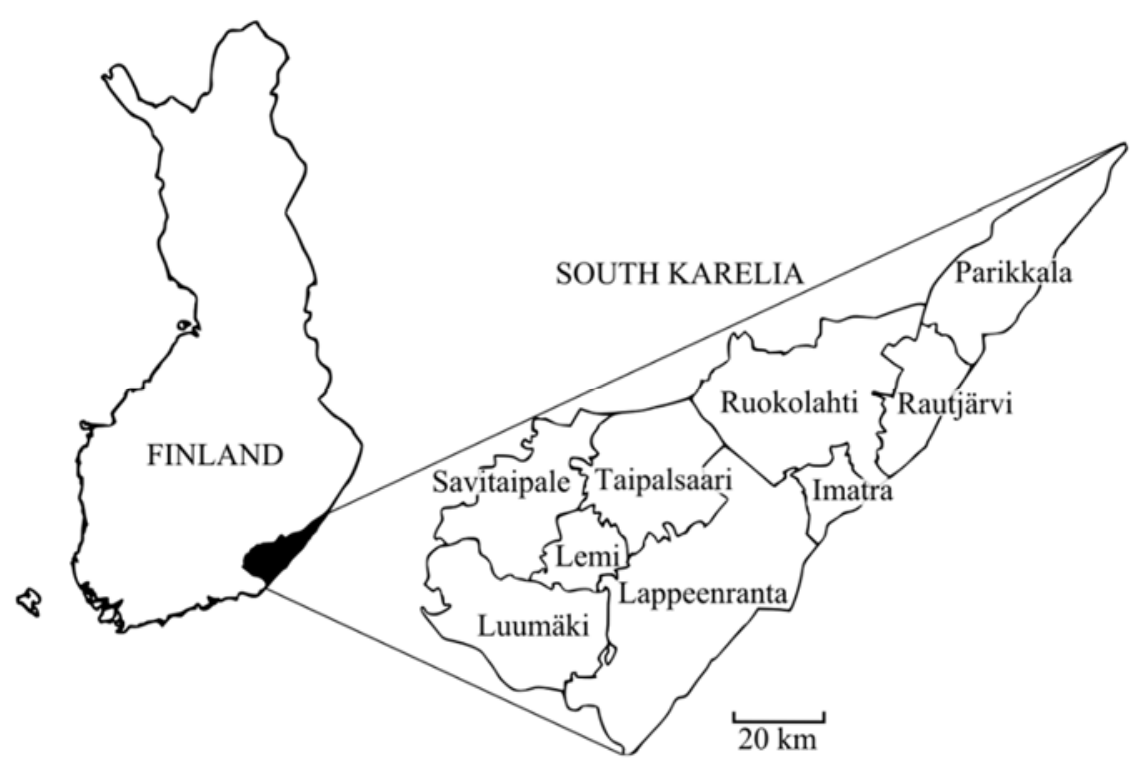

Figure 1: The South Karelia region. 


\subsection{Waste stream analysis}

The VAHTI database, a monitoring system for the Finnish environmental administration, was used as the primary source of information in this study. Operators that hold an environmental permit report their annual waste data to the VAHTI database and the database is the primary information source for national waste statistics. The study references regional waste stream data from the year 2016 only.

Operators are obligated to record three different waste flows in the database. The first flow type is received waste. Received waste describes a facility's incoming waste streams. Received waste is either treated (recovered, disposed of or otherwise treated, e.g. pre-treated or sorted) in a facility, stored or diverted for further treatment. The second flow type is generated waste, which can be described as the waste streams that leave a facility. If waste is not either treated or stored in the facility that initially receives the waste it may be counted twice as both received and generated waste. The third flow type is stored waste. Operators are obligated to record their storage situation at the end of each year. Of the above-mentioned flow types, only received waste streams are analysed in this study. The main reason for this is the issue of the possible double-counting of waste streams. No information is available on the double-counting of received and generated waste. Therefore, to avoid the misrepresentation of these waste flows, generated waste is not analysed here. Additionally, received waste composes a substantially larger waste flow than either generated or stored waste. Hence, we conclude that received waste represent regional $C \& D$ waste generation with sufficient accuracy.

The European waste catalogue (EWC) codes of the above-mentioned waste flows are recorded in the VAHTI database. The EWC codes are used in the study to identify how much $C \& D$ waste is generated in the South Karelia region. EWC codes consist of three pairs of numbers in a "00-00-00" format. The first two numbers indicate the origin of the recorded waste. The number 17 indicates that waste has originated from the C\&D industry. This waste is defined as "construction and demolition wastes (including excavated soil from contaminated sites)" [8].

In addition to the EWC codes, the treatment method of the received waste must be recorded in the database. The recovery (R) and disposal (D) codes are defined in the Waste Framework Directive (2008/98/EC) [1]. The calculation of recovery and disposal rates is fairly straightforward since it is represented by RD codes, whereas the calculation of the material recovery rate is slightly more complex. The following $\mathrm{R}$ codes were regarded as indicating material recovery in the study:

- $\quad \mathrm{R} 02=$ Solvent reclamation/regeneration;

- $\quad \mathrm{R} 032=$ Composting of organic waste;

- $\quad \mathrm{R} 033$ = Anaerobic digestion of organic waste;

- $\mathrm{R} 035=$ Other material recovery of organic waste;

- $\quad \mathrm{R} 041=$ Recovery and pre-treatment of metals;

- $\quad \mathrm{R} 042$ = Material recovery of metals;

- $\quad \mathrm{R} 052$ = Material recovery of inorganic waste;

- $\quad$ R06 = Regeneration of acids or bases;

- $\quad \mathrm{R} 08=$ Recovery of components from catalysts;

- $\quad \mathrm{R} 09=$ Oil re-refining or other reuses of oil. 


\subsection{Mixed C\&D waste composition study}

A composition study of mixed C\&D waste was conducted to identify the mass-based composition of mixed C\&D waste samples in the South Karelia MSW management centre. Mixed C\&D waste is waste that has not been source-separated into different waste components (e.g. plastic, metal, wood). Mixed C\&D waste will normally go through a process of mechanical separation, where specific waste components are separated from each other for further treatment.

The study was conducted in the summer of 2017. Six mixed C\&D waste samples (loads) were analysed. The following steps were taken in the study. First, C\&D waste was unloaded from trucks. Then C\&D waste was spread out using a wheel loader. After that, samples were taken from the waste piles. Since the total mass of the waste piles was several tonnes, the waste piles were not sorted in their entirety due to time constraints. Therefore, individual sub-samples were taken from the C\&D waste piles. The samples were taken on the basis of a visual evaluation, the selection criterion of which required that the sample represent the waste pile as accurately as possible. For example, if plastic composed the majority of the waste pile based on a visual evaluation, the majority of the sample taken ought also to be plastic. This approach has inevitably influenced the statistical reliability of the study. However, as the study is an individual case study, the visual evaluation method was concluded to be a sufficiently accurate sampling method in the context. In order to draw more definite conclusions about the composition of mixed C\&D waste, more established and reliable sampling methods ought to be applied in future research.

In total, $1,951 \mathrm{~kg}$ of C\&D waste was manually sampled and weighed. Since the mass of samples varied, sample mass was normalised to $100 \mathrm{~kg}$ (see eqn (1)). Thus, each sample is represented equally in the total results (see eqn (2)). The main research methodology for the mixed C\&D waste composition study is summarised in Fig. 2.

$$
N M=\sum_{i=1}^{n} \frac{x^{1}}{z^{1}} * P+\frac{x^{2}}{z^{2}} * P+\cdots+\frac{x^{n-1}}{z^{n-1}} * P+\frac{x^{n}}{z^{n}} * P,
$$

- $\quad n$ is the number of samples;

- $\quad N M$ is the normalised mass of a waste component (e.g. wood or plastic);

- $\quad x$ is the mass of a waste component in a sample;

- $\quad z$ is the mass of a sample;

- $\quad P$ is the predefined mass used to normalise the results (in this instance, $100 \mathrm{~kg}$ )

$$
A S=\frac{N M}{n * P}
$$

- $A S$ is the average share of a waste component.

\section{RESULTS AND DISCUSSION}

\subsection{C\&D waste streams in the South Karelia region}

In total, approximately $1,183,000$ tonnes of waste were received in the South Karelia region in 2016. The origin of waste can be identified based on the first two digits of the waste stream's EWC code (see Fig. 3). The pulp and paper industry plays a significant role in the industrial sector in the South Karelia region. Its importance is reflected clearly in the waste streams recorded: approximately $57 \%$ of received waste in the region originated from the 
Sample trucks

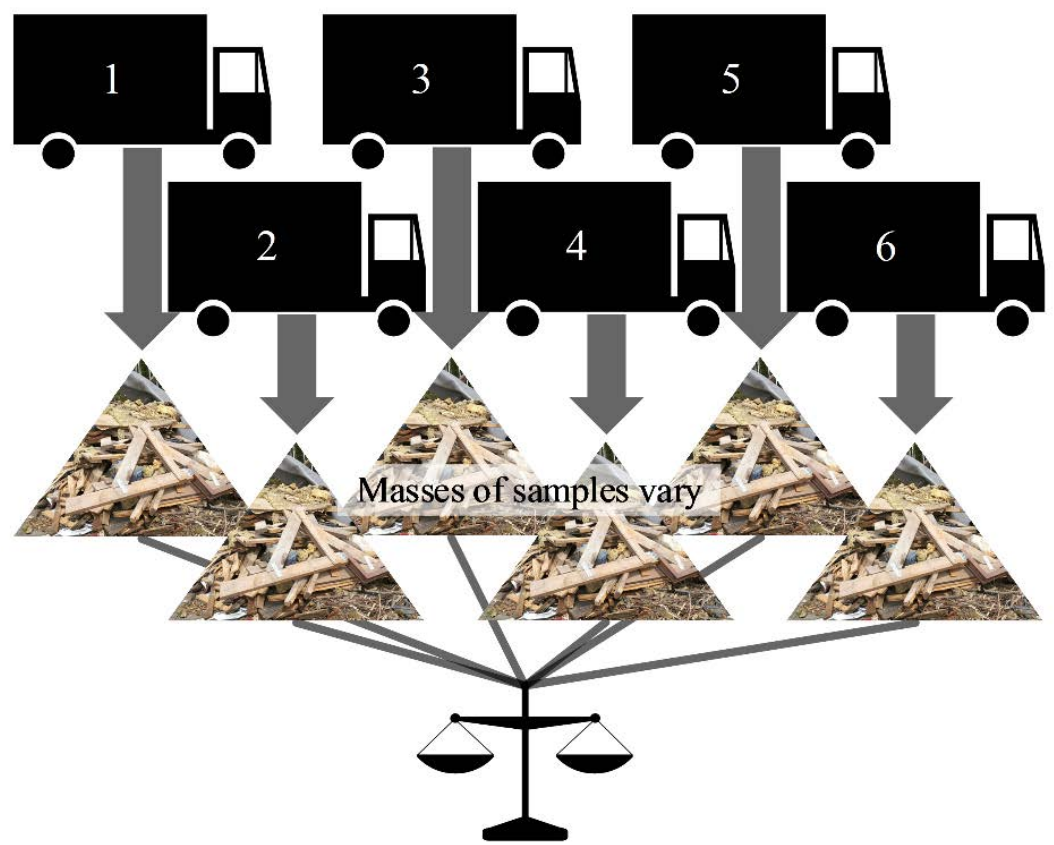

Sampling and weighting
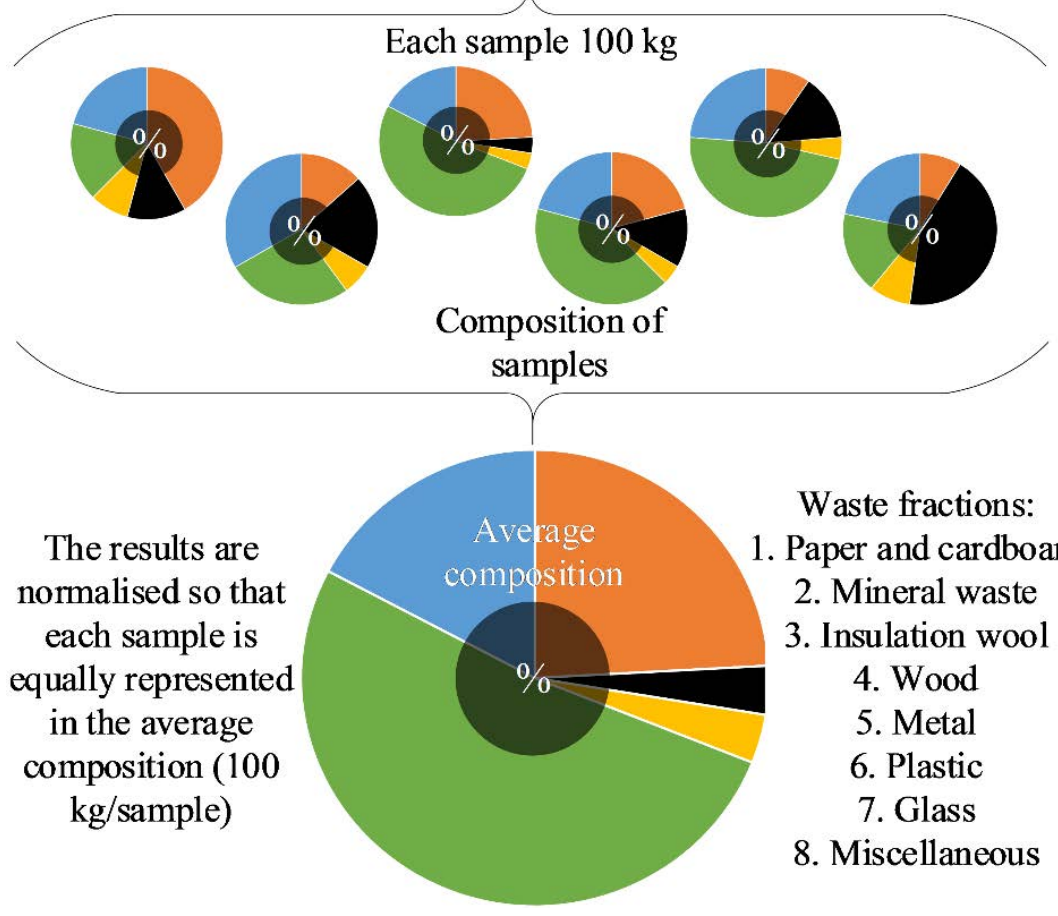

Waste fractions:

1. Paper and cardboard 2. Mineral waste 3. Insulation wool

4. Wood

5. Metal

6. Plastic

7. Glass

8. Miscellaneous

Figure 2: The main research methodology of the C\&D waste composition study. 


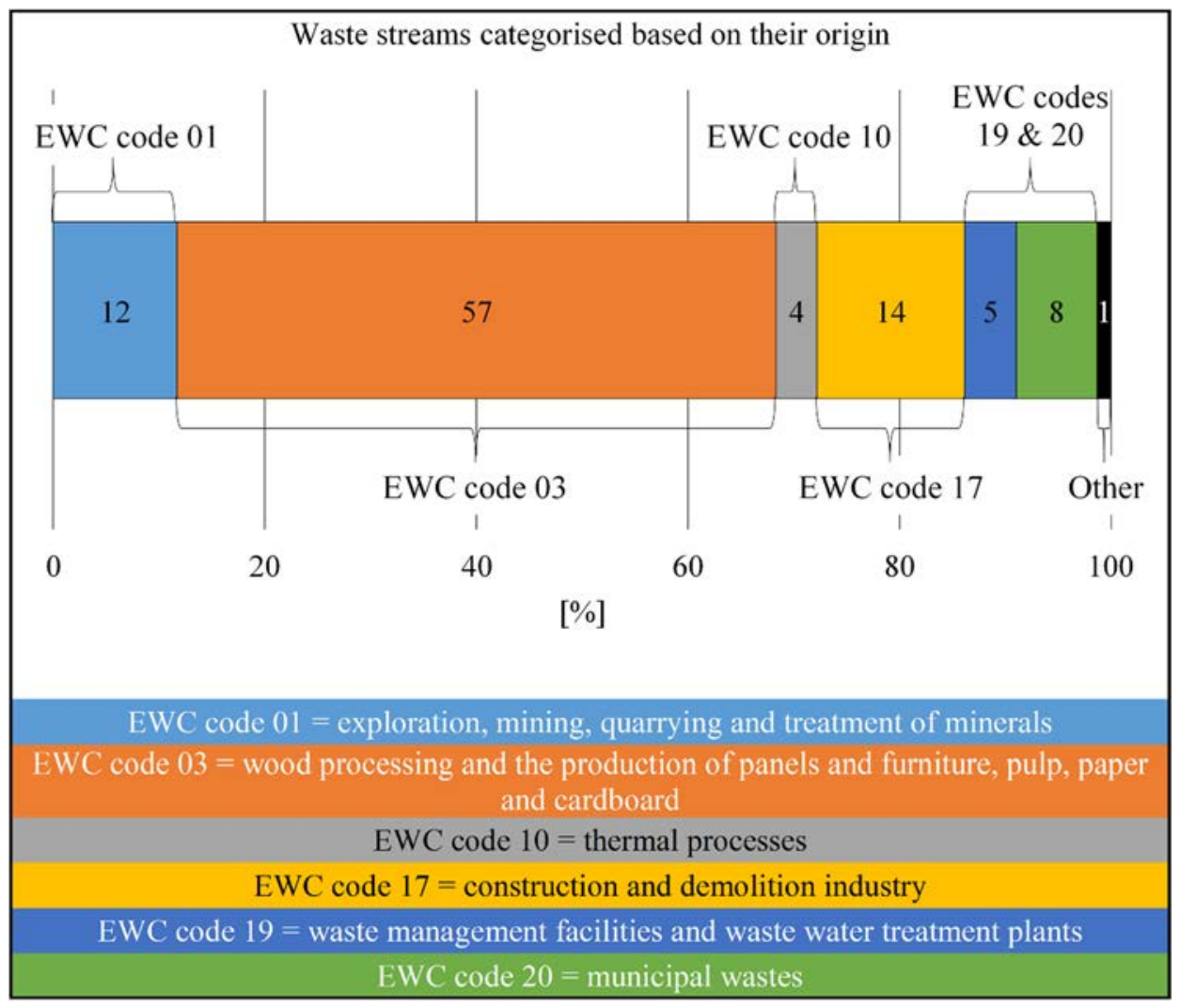

Figure 3: Received waste streams in the South Karelia region in 2016 categorised according to origin (i.e. the first part of the EWC codes).

wood processing industry, more precisely from pulp and paper industry, in 2016. Of the tonnes of waste received in the South Karelia region in 2016, 165,000 tonnes were C\&D waste. This equates to $14 \%$ of all received waste streams in the region in 2016 .

Received C\&D waste streams are classified according to their EWC codes, as illustrated in Table 1. As can be seen, other C\&D waste constitutes 6.4\% (approximately 10,500 t/a) of all $C \& D$ waste, which is rather high compared with, for example, the share of wood, glass and plastic in all C\&D waste. However, no information about the composition of other C\&D waste is available. This raises two key questions: what precisely is mixed C\&D waste, and what is its material recovery potential?

The recovery and disposal rates of waste streams can be assessed according to their RD codes. Recovery rate can be sub-divided into material recovery and other recovery (i.e. recovery other than material recovery). The disposal, material recovery and other recovery rates of all waste streams and C\&D waste are presented in Fig. 4. As can be seen, in 2016, the disposal rate of all waste was $19 \%$, whereas the disposal rate of C\&D waste was $6 \%$. The material recovery rate of $C \& D$ waste was notably higher than for all recorded waste streams: $43 \%$ versus $15 \%$. In Finland, 58\% of C\&D waste was recovered as material in 2014 [3]. Considering this, further action is needed to reach the EU's $70 \%$ material recovery target by 2020 both at a national and particularly at a regional level. 
Table 1: C\&D waste streams categorised according to EWC codes.

\begin{tabular}{|c|l|c|c|}
\hline EWC code & Definition & Mass (t/a) & Share (\%) \\
\hline $17-01$ & Concrete, bricks, tiles and ceramics & 56,300 & 34.1 \\
\hline $17-02$ & Wood, glass and plastic & 6,400 & 3.9 \\
\hline $17-03$ & Bituminous mixtures, coal tar and tarred products & 800 & 0.5 \\
\hline $17-04$ & Metals (including their alloys) & 52,200 & 31.7 \\
\hline $17-05$ & $\begin{array}{l}\text { Soil (including excavated soil from contaminated } \\
\text { sites), stones and dredging spoil }\end{array}$ & 37,400 & 22.7 \\
\hline $17-06$ & $\begin{array}{l}\text { Insulation materials and asbestos-containing } \\
\text { construction materials }\end{array}$ & 1,300 & 0.8 \\
\hline $17-09$ & Other construction and demolition waste & 10,500 & 6.4 \\
\hline \multicolumn{2}{l}{} & 164,800 & 100.0 \\
\hline
\end{tabular}

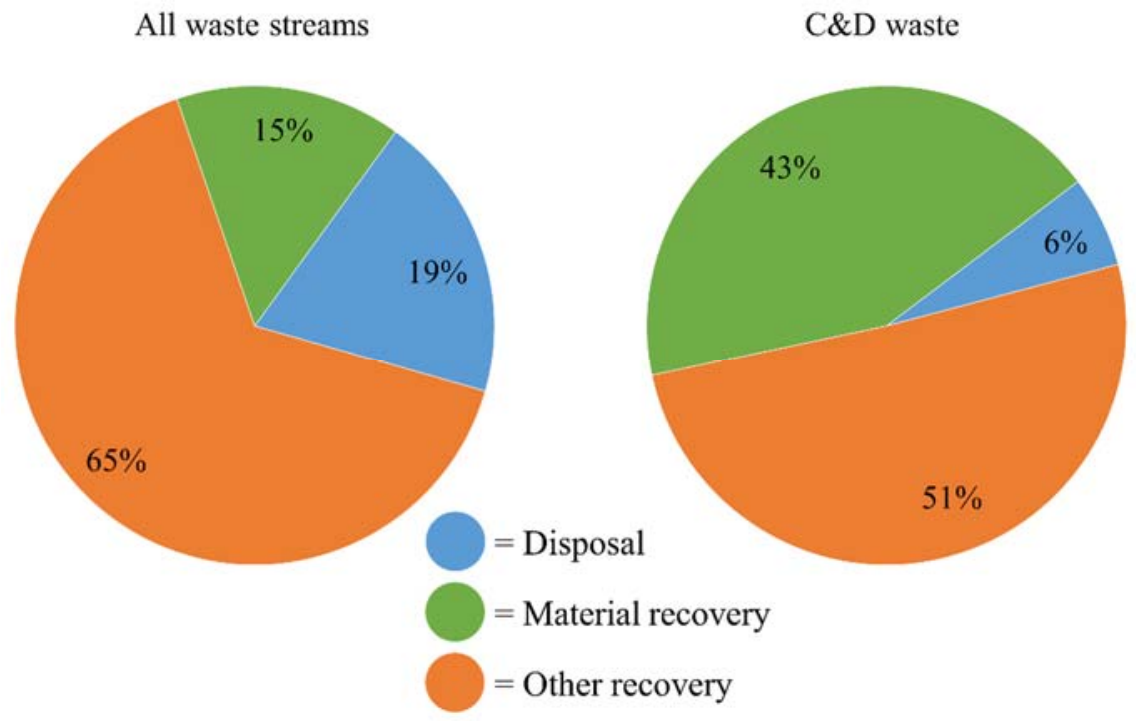

Figure 4: Disposal, other recovery (excluding material recovery) and material recovery rates of waste streams in the South Karelia region in 2016.

The disposal, material recovery and other recovery rates of C\&D waste are analysed in further detail in Fig. 5, where specific treatment rates for waste streams are considered. The waste streams discussed are those introduced in Table 1. Of particular note are the following observations from the figure. The highest material recovery rate was achieved in the 17-04 category, which is metals. The material recovery rate for this category was $92 \%$. Additionally, the material recovery rate of 17-05, that is, soil, stones and dredging spoil, was high: $57 \%$. These categories also represent a high share of overall C\&D waste. Therefore, their material recovery significantly increases the total material recovery rate of all C\&D waste. The highest disposal rate is detected in the 17-06 category, which is insulation materials and asbestos-containing construction materials. For non-hazardous insulation materials (e.g. mineral wool), landfill disposal is currently the predominant treatment method in Finland. However, material recovery may well be a viable alternate treatment method. 


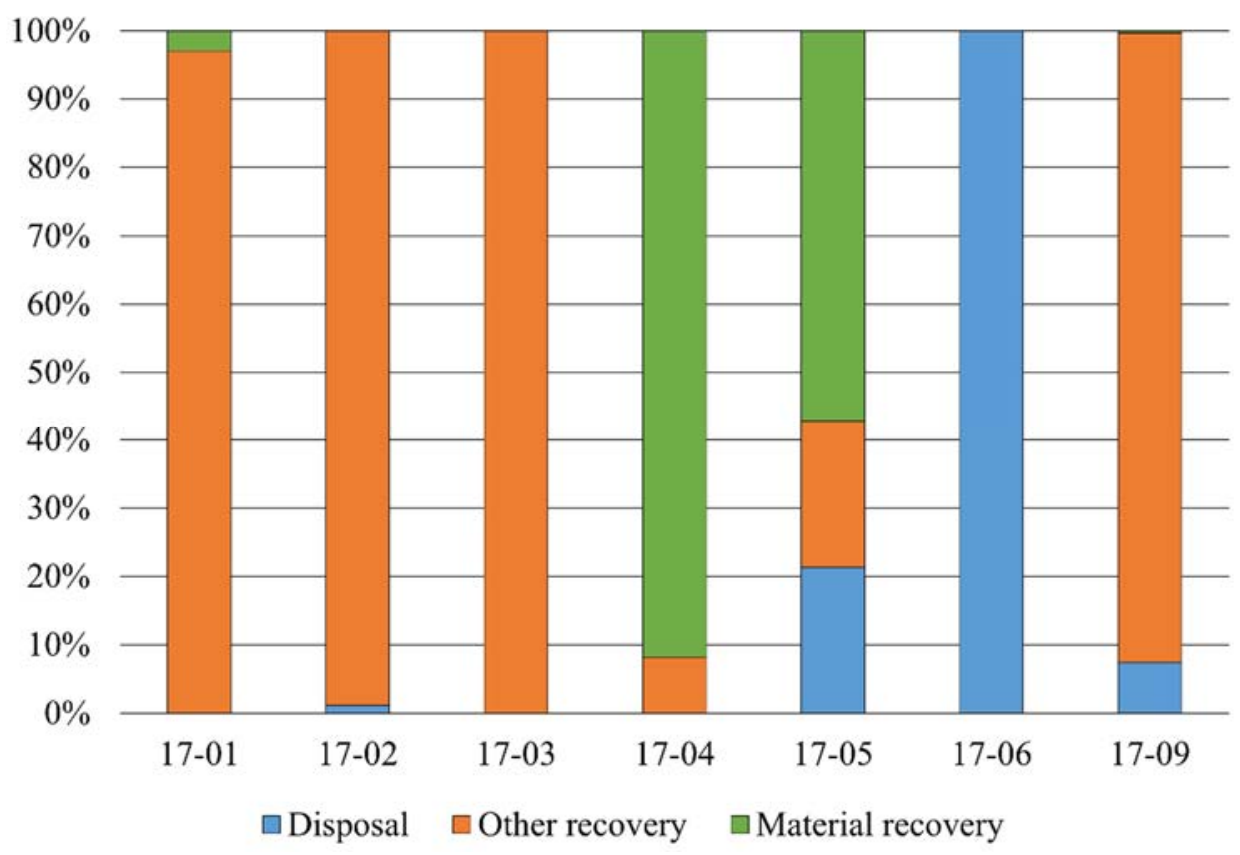

Figure 5: Disposal, other recovery (excluding material recovery) and material recovery rates of C\&D waste streams in the South Karelia region in 2016.

Mineral wool can, for example, be used as a filler material in composite production [9]. The material recovery rate of category $17-01$, that is, concrete, bricks, tiles and ceramics, was low (3\%) given that concrete can be utilised in earth construction, for instance. The reason behind this low figure is that most of the waste in this group was recorded under the code R51, which indicates the recovery and pre-treatment of inorganic waste. No further information about this recovery method is available, and therefore, it was regarded as belonging to the other recovery method. In contrast, the code R52 represents the material recovery of inorganic waste.

\subsection{Composition of mixed C\&D waste}

The average composition of the sorted mixed C\&D waste samples was determined using the steps described in Section 3.2. Following the described steps, each sample is represented equally in the average composition figures. As can be seen from Fig. 6, the average composition of C\&D waste is made up, among other things, of mineral waste $(25 \%)$, wood $(26 \%)$ and plastic (18\%). These elements thus constitute the vast majority, nearly $70 \%$, of the average composition of mixed C\&D waste.

The analysis of the composition of the mixed C\&D samples reveals that they contain a notable proportion of materials that are suitable for material recovery. Finland has an established material recovery system for paper and cardboard, which accounted for $7 \%$ of average $C \& D$ waste composition according to our analysis [10]. Therefore, material recovery of these components can be considered to be straightforward in comparison with some other C\&D waste elements. 


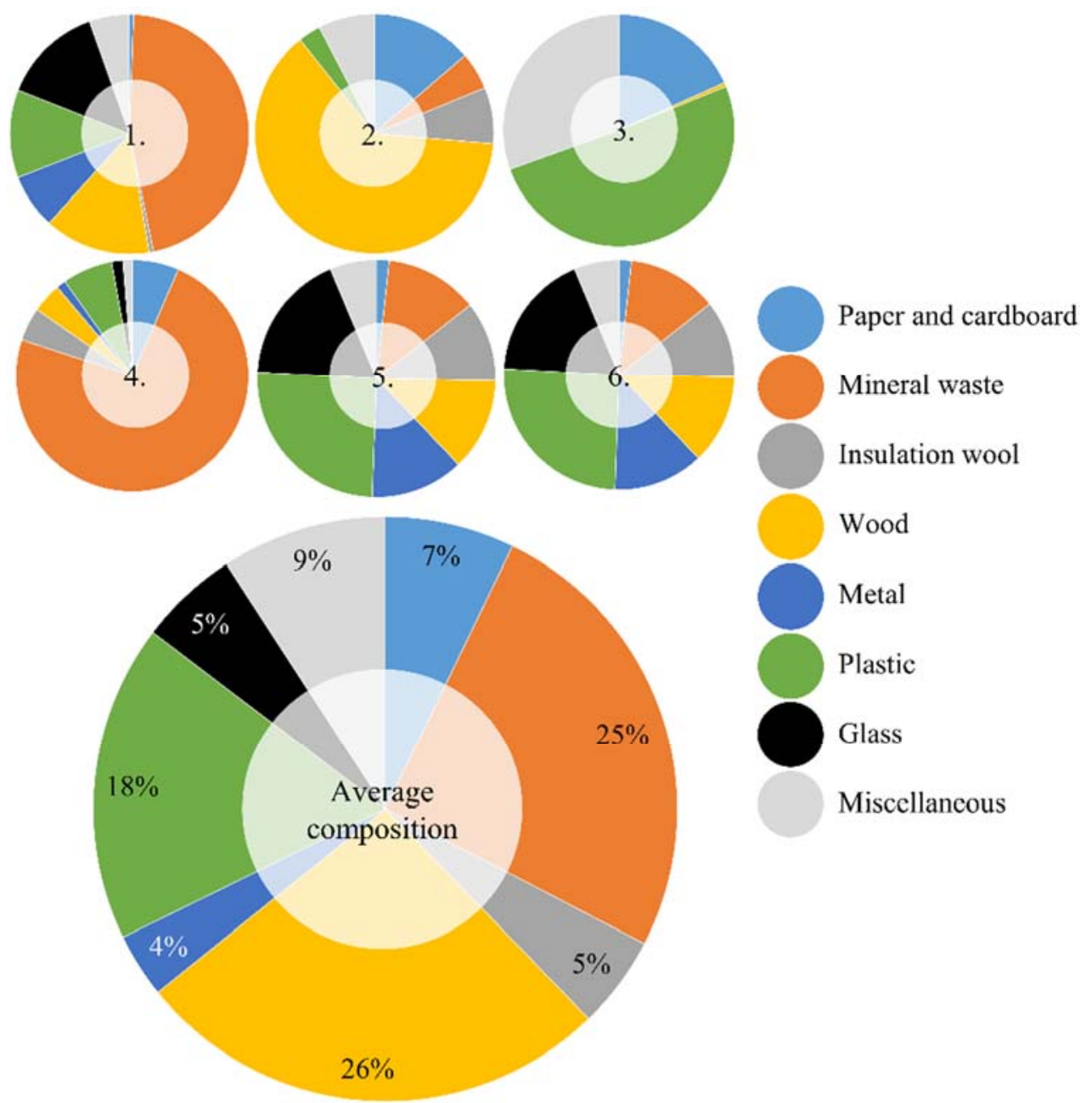

Figure 6: The composition of mixed C\&D waste based on manually sorting six different samples.

Mineral waste (e.g. concrete, bricks and tiles) was found to constitute $25 \%$ of the average composition of mixed C\&D in our study. Mineral waste can be recovered as material when, for example, it utilised in earth construction [11]. However, its utilisation in earth construction is subject to both legislative and technical restrictions to minimise the associated environmental impact. Therefore, the material recovery possibilities of mineral must be studied and evaluated on a case by case basis. Insulation wool composed 5\% of the mixed C\&D samples. Currently, there is no established material recovery method for insulation wool in Finland, but emerging technologies have been identified and developed. For example, composite production has been identified as a potential treatment method for insulation wool [9].

Wood is a problematic material in terms of material recovery. Material recovery methods for wood do exist in Finland, but, energy recovery has thus far been the most feasible 
treatment method for wood and therefore it is the predominant treatment method for wood in Finland [10]. However, the material recovery target introduced by the EU have placed pressure on Finland to change this practice in the coming years. Composite production has been identified as an additional potential treatment method for C\&D waste wood [12]. Metal, a valuable material, has a well-established material recovery system in Finland [10]. This may well be the primary reason behind the low percentage of metal remaining in mixed C\&D waste (4\%). In contrast, plastic was found to compose a notable share of mixed C\&D waste in our study: $18 \%$. The recoverability of plastic as a material depends heavily on the type of plastic being recovered [13]. In Finland, there are currently separate collection system and material recovery plant exclusively for plastic packaging. This has highlighted the need for alternative treatment methods, and composite production, for example, has been proposed as a treatment method for C\&D waste plastics [12].

The share of glass in the C\&D waste samples analysed was quite low at $6 \%$. There is a well-established material recovery system for glass packaging in Finland [10]. However, glass from the C\&D industry is usually more difficult to reclaim since it has typically been treated with various additives, hindering recoverability. Finally, the proportion of miscellaneous waste in the C\&D waste samples was $9 \%$, which can be considered a reasonable amount of unspecified waste. Unidentified fine fraction, for instance, was included in this category. The average composition of the sorted mixed C\&D waste samples is presented in Fig. 6. The composition of individual samples is presented in the same figure.

\section{CONCLUSIONS}

This study focused on C\&D waste streams in the South Karelia region, Finland. Approximately 1,180,000 tonnes of waste were generated in the South Karelia region in 2016 of which 14\% (approximately 165,000 tonnes) was generated by the C\&D waste industry. Taking a closer look at the C\&D waste generated, it can be seen that mineral waste, metals and soils are the main contributors of C\&D waste. In total, these components were found to constitute nearly $90 \%$ of the total C\&D waste generated in the region. The proportion of mixed C\&D waste was also notable: approximately $6 \%$. No information is available on the material composition of mixed C\&D. Thus, we analysed the composition of mixed C\&D waste by manually sorting different samples. The manually analysed mixed C\&D waste samples indicated significant material recovery potential given that minerals, wood and plastic composed approximately $70 \%$ of these samples. By combining the information on the composition of mixed C\&D waste with the information on C\&D waste streams, the overall composition of regional C\&D waste streams can be formed which will facilitate the identification of regional material recovery potential.

\section{ACKNOWLEDGEMENTS}

This study was conducted as part of the CIRCWASTE project funded by the European Commission and the FISS South Karelian Industrial Symbiosis Service project funded by the European Regional Development Fund.

\section{REFERENCES}

[1] European Commission Directive, Directive of the European Parliament and of the Council of 19 November 2008 on waste and repealing certain directives. Official Journal Of the European Union L, 312(3), p. 98, 2008.

[2] European Commission, Resource efficient use of mixed wastes. Online. ec.europa.eu/environment/waste/studies/mixed_waste.htm. Accessed on: 15 Jun. 2018. 
[3] Salmenperä, H. et al., Policy instruments for increasing waste recycling. Online. tietokayttoon.fi/julkaisu?pubid=15201. Accessed on: 15 Jun. 2018.

[4] European Commission, Construction and Demolition Waste (CDW). Online. http://ec.europa.eu/environment/waste/construction_demolition.htm. Accessed on: 15 Jun. 2018.

[5] Statistics Finland, Waste generation in 2015. Online. http://pxnet2.stat.fi/PXWeb/pxweb/en/StatFin/StatFin_ymp_jate/statfin_jate_pxt_0 03.px/?rxid=4850f308-c36f-4bf5-9c97-9c33ab889366. Accessed on: 15 Jun. 2018.

[6] Menegaki, M. \& Damigos, D., A review on current situation and challenges of construction and demolition waste management. Current Opinion in Green and Sustainable Chemistry, 13, pp. 8-15, 2018. DOI: 10.1016/j.cogsc.2018.02.010.

[7] Statistics Finland, Population. Online. www.tilastokeskus.fi/tup/suoluk/ suoluk_vaesto.html. Accessed on: 15 Jun. 2018.

[8] European Commission, Commission Decision on the European List of Waste (2000/532/EC).

[9] Väntsi, O. \& Kärki, T., Utilization of recycled mineral wool as filler in woodpolypropylene composites. Construction and Building Materials, 55, pp. 220-226, 2014.

[10] Piippo, S., Municipal solid waste management in Finland. Online. nortech.oulu.fi/ GREENSETTLE_files/Municipal\%20solid\%20waste $\% 20$ management $\% 20 \mathrm{in} \% 20 \mathrm{Fin}$ land.pdf. Accessed on: 15 Jun. 2018.

[11] Wahlström, M., Laine-Ylijoki, J., Määttänen, A., Luotojärvi, T. \& Kivekäs, L., Environmental quality assurance system for use of crushed mineral demolition wastes in earth constructions. Studies in Environmental Science, 71(C), pp. 725-734, 1997.

[12] Keskisaari, A. \& Kärki, T., The use of waste materials in wood-plastic composites and their impact on the profitability of the product. Resources, Conservation and Recycling, 134, pp. 257-261, 2018. DOI: 10.1016/j.resconrec.2018.03.023.

[13] Dahlbo, H., Poliakova, V., Mylläri, V., Sahimaa, O. \& Anderson, R., Recycling potential of post-consumer plastic packaging waste in Finland. Waste Management, 71, pp. 52-61, 2018. DOI: 10.1016/j.wasman.2017.10.033. 